\title{
An Evaluation of the Practicality of Sliding Mode Controllers in DC-DC Converters and Their General Design Issues
}

\author{
Siew-Chong Tan, Y. M. Lai, and Chi K. Tse \\ Department of Electronic and Information Engineering \\ The Hong Kong Polytechnic University, Hong Kong, China \\ email: ensctan@eie.polyu.edu.hk
}

\begin{abstract}
This paper examines the practical design issues of sliding mode controllers as applied to the control of DCDC converters. A comprehensive review of the relevant literature is first provided. Major problems that prevent the use of sliding mode control in DC-DC converter for industrial applications and their possible solutions are discussed. Performance of sliding mode control is compared with that of conventional PWM control in terms of transient characteristics. It is shown that the use of sliding mode control can lead to improved robustness in providing consistent transient responses over a wide range of operating conditions.
\end{abstract}

\section{INTRODUCTION}

The sliding mode (SM) controller was introduced for controlling variable structure systems (VSS) [1]-[5]. Its major advantages are guaranteed stability and robustness against variations and uncertainties [1]. It has a high degree of design flexibility and is relatively easy to implement as compared to other types of nonlinear controllers. This explains its wide utilization in various industrial applications, e.g. automotive control, furnace control, etc. [3].

Characterized by switching, DC-DC converters are inherently variable structured. It is appropriate to use SM controllers in DC-DC converters [6]. This seems more naturally so since the design of conventional pulsewidth modulation (PWM) controllers in power electronics is small-signal based [7] and they often perform unsatisfactorily under large-signal operating condition [8]-[10]. It is known that the use of SM (nonlinear) controllers can maintain a good regulation for a wider operating range. This has aroused a lot of interests in the use of SM controllers for DC-DC converters [11]-[69].

However, despite being a popular research subject, SM control is still rarely applied in practical DC-DC converters. There are various reasons accommodating this. Firstly, unlike PWM controllers, SM controllers are not available in integrated circuits (IC) forms for power electronics applications. Secondly, there is a lack of understanding in its design principle by power supply engineers. Thirdly, there is a strong reluctance to employing SM controllers in DC-DC converters because of their inherently high and variable switching frequency. Fourth, all discussions regarding the usefulness and advantages of SM controllers have been theoretical. The practical worthiness of using SM controllers is generally unproven. In essence, SM controllers are not used in practical DC-DC converters because of the inconvenience of using them, as well as the lack of strong evidence to support the need for using them.
Hence, the objective of this paper is to present an overall discussion to clarify the different aspects of the application of sliding mode controllers in DC-DC converters. A comprehensive literature review is conducted to update peer engineers the major developments in the area. The various problems of applying SM controllers to DC-DC converters are discussed. The practical issues related to its implementation are also addressed. Finally, the advantages of using SM controllers as compared to conventional PWM controllers are discussed through some case study examples.

\section{Literature REVIEW}

Earliest Works: The earliest works on developing SM controllers for DC-DC converters are reported in 1983 [11] and 1985 [12]. These works demonstrated how SM controllers can be applied to various basic topologies of second-order DC-DC converters. The idea of relating the equivalent control method of SM control theory to the duty ratio control method of PWM technique can also be found in [12].

Higher Order Converters: In 1989, Huang et al. [13] experimented the SM controller on a more complex fourthorder Ćuk converter. This spurred a series of related works on the Ćuk converter [14]-[19]. In particular, Mahdavi et al. [17] developed the first PWM based SM controlled Ćuk converter in 1996. Concurrently, the work by Huang et al. [13] also generated new interests on other types of higher order DCDC converters, namely, Ćuk, Sepic, and quantum resonant converters [20]-[23].

Parallel-Connected Converters: The interest in applying SM control to more complex types of DC-DC converters has also covered the class of parallel-connected DC-DC converters. The objective is to achieve better current equalization and output voltage regulation of modular DC-DC converters through SM control [24]-[31].

Theoretical Works: Due to simplicity and ease of analysis, simple second-order DC-DC converters have been the subjects of investigation in much of the previous work. These earlier studies have played an important role in the development of practical SM controllers for DC-DC converters. The main focus was the theoretical derivation of SM control methodologies [32]-[44]. Theoretical evaluations and comparisons with other control methods were also reported [45]-[49].

Practical Works: A few experimental evaluations of SM controlled DC-DC converters have been reported in the literature [50]-[55]. Most of the reported experimental works, however, focused their attention on performance evaluation rather than on developing design procedures, which are critical for engineering practices. 
Constant Frequency SM controllers: Some researchers have noted the importance of maintaining a constant switching frequency operation in their SM controllers. Various methods have been proposed for the purpose [31], [56]-[62]. SM control has, in most cases, been studied in continuous time. A few attempts to study its discrete-time counterparts have been reported [63], [64]. It was argued that the discretetime implementation of the SM controller could overcome the inherent drawbacks of variable switching frequency operation in the conventional continuous-time implementation.

Remarks: We summarize the major developments of SM control in DC-DC converters as follows. Firstly, the idea of applying SM (nonlinear) control in high order converters is acceptable because linear controllers are incapable of providing good control over such systems. Higher design and implementation costs are easily justified in such circumstances. However, the idea of applying SM controllers to basic second-order DC-DC converter is often challenged. The main complaint is its conceptual/implementational complexity as compared to existing PWM controllers, which are already offering acceptable control properties in such converters for most applications. Moreover, the notion of using expensive digital means to implement these controllers, as illustrated in many previous attempts, have been deemed unrealistic for commercial applications. Still, it is important to find out what the benefits and drawbacks of using SM controllers are, as compared to existing linear PWM controllers, assuming that we manage to implement the former in a comparable form and cost to the latter

Secondly, a large part of the previous effort has been devoted to developing the theoretical framework of SM control for DC-DC converters. Practical work, however, has been neglected due to the conventional belief that the control schemes can be easily realized in digital forms. Thus, the interest in its development normally halts at the theoreti$\mathrm{cal} /$ mathematical stages. However, if SM controllers are to be implemented for commercial applications, thorough studies of practical problems are necessary. Specifically, the different means of developing analog SM controllers, which operate at a constant switching frequency that complies with industrial standards, should be explored. Obviously, a contradiction exists between the ideal operation of SM controllers at infinitely high frequency and such controllers. Hence, while aiming at competitive pricing and comparable standard to existing PWM controllers, there must also be considerations on how the non-ideality of constant frequency can be compromised without sacrificing the large signal properties of SM control. Essentially, more investigations into such aspects are required.

\section{Sliding Mode Controllers}

This section discusses the various aspects of the SM controllers specific to applications in DC-DC converters.

An Ideal Controller: The basic principle of SM control is to employ a certain sliding surface as a reference path, such that the controlled state variables' trajectory can be directed towards the desired equilibrium. Theoretically, such ideology can only be achieved with the absolute compliances of certain conditions, namely the hitting condition, the existence condi- tion, the stability condition, and the condition that the system operates at an infinite switching frequency. In such respect, what is derived is an idealized controlled system, whereby no external disturbances or system's uncertainties can affect the ideal control performance of having zero regulation error and very fast dynamic response. In a way, the SM controller is a type of ideal controller for the class of VSS. A detailed discussion of the SM control principle can be found in [1].

Constant Dynamics: An interesting property of the SM controller is that it is possible to ensure an almost constant dynamical characteristic for all operating conditions through the proper choice of sliding coefficients [68]. This is not the case for conventional types of linear PWM controllers. The small-signal structure of the linear controllers allows the dynamics of the system to be characterized at only one specific operating condition. When the operating condition differs the nominal condition, the dynamical response of the system will be different. A comparison of these properties is given in the later part of the paper.

Quasi-Sliding Mode Control: Extreme high speed switching in DC-DC converters results in excessive switching losses, inductor/transformer core losses, and EMI noise issues. Hence, for SM controllers to be applicable to DC-DC converters, their switching frequencies must be constricted within a practical range. However, such constriction transforms the controller into a type of quasi-sliding mode (QSM) controller, which operates as an approximation of the ideal SM controller. The consequence is the reduction of the system's robustness and the deterioration of the regulation property. Typically, the term SM controller has been adopted to represent QSM controller.

Conventional Hysteresis Modulation Based Sliding Mode Controller: The conventional method of implementing the SM controller is based on the signum function type of switch relay. However, as discussed, it is necessary to suppress the operating frequency to within the practical limits of the converters. Many methods have been proposed. The most popular one is the hysteresis modulation (HM) method. The main advantage is that the implementation does not require additional computation or auxiliary circuitries, and it is easily accomplished by introducing a layer of hysteresis band into the signum function [65]. This method allows the switching frequency to be suppressed into a controllable form determinable by the width of the hysteresis band.

\section{The NeEd For FIXed-Frequency SM Controller}

It is shown that HM based SM controlled converters generally suffer from significant switching frequency variation when the input voltage and the output load are varied [20], [65]. This complicates the design of the input and output filters, and also deteriorates the regulation of the converters [66]. Moreover, switching converters are severe noise generators. The task of containing noise is easier with fixed-frequency operation. Therefore, it is essential for converters to operate at a constant frequency.

There are basically two approaches in keeping the switching frequency of the HM based SM controller constant. One approach is to incorporate a constant ramp or timing function directly into the controller [20], [56], [62]. Its main advantage 
is that the switching frequency is absolutely constant at all operating conditions. However, the disadvantages are additional hardware circuitries and deteriorated transient response. The second approach is to include some forms of adaptive control into the HM based SM controller [57], [66]. These methods are more direct and less likely to suffer from deteriorated transient response. However, the architecture of the resulting controller is relatively complex, and may increase the implementation cost of the controller. Moreover, the switching frequency is not absolutely constant [66].

On the other hand, constant-frequency SM controllers can also be obtained by employing PWM in lieu of HM, without destroying the SM control properties [58], [66]. This requires the relationship of the two control techniques to be established. Two key results are useful here. First, in SM control, the discrete control input (gate signal) $u$ can be replaced by a smooth function known as the equivalent control signal $u_{\mathrm{eq}}$ [1]. Second, at a high switching frequency, the equivalent control is effectively a duty cycle control [71]. Since a duty cycle is a smooth analytic function of the discrete control pulses in PWM, a PWM based SM controller can be obtained by mapping the equivalent control onto the duty cycle function of the pulsewidth modulator, i.e., $d=u_{\text {eq }}$. The advantages of this approach are that additional hardware circuitries are not needed as the switching function is performed by the PWM modulator, and that the transient response is not deteriorated. However, the implementation is non-trivial in order to preserve the original SM control law.

\section{IMPLEMENTATION ISSUES: ANALOG VIEWPOINT}

There is little work addressing the practical aspects of implementing the SM controller for DC-DC converters, especially in the area of analog implementation. The issue of requiring constant frequency have been pinpointed [56]-[64]. Here are few more aspects that also deserve consideration. Firstly, the choice of system's state variables, i.e., voltage, current, their derivatives and/or integrals, is important in that it affects not only the control performance, but also the complexity of the implementation. These are some questions that we should consider:

1. How many state variables to control?

Comment: The higher the number of state variables, the higher the degree of system's controllability. However, more sensing and/or computation of the state variables are required.

2. Which state variables to control?

Comment: The use of voltage state variables is easier because of the simplicity of implementing voltage sensors. However, the choice for their derivatives may require the use of noise sensitive differentiators. Alternatively, indirect means of sensing such state variables is possible, e.g. $d v_{\mathrm{o}} / d t$ can be found by sensing the current of the output capacitor. Yet, this will lead us to the subsequent question as to whether it is convenient to perform such sensing. On the other hand, an integral term of the controlled variable $\int x$ is often required to reduce the steady-state error of the system, which may otherwise exceed the regulation requirement. Moreover, in cases of non-minimum phase converters, the control of the voltage state variables alone is incapable of providing optimal control performances. It is necessary to include also the inductor current into the control. This would mean additional sensors and computations.

3. Is the location accessible or feasible for such sensing? Comment: The sensing of capacitor current to find the derivative of voltage variable is not always the best option. This is especially true for the case where the capacitor is a filter capacitor. Addition of a current sensor in its current flow path will increase the impedance, and therefore deteriorate the filtering process.

4. Which type of sensors are required?

Comment: For the sensing of the filtering capacitors' currents, very low impedance current transformers are normally required. However, for sensing currents that have DC average components, resistors or sophisticated hall-effect sensors may be required. These may affect the overall efficiency or cost of the DC-DC converters.

Moreover, for the PWM based SM controllers, the indirect implementation of the original SM control law may result in unexpected complications in the signal computation. It is not implementable for some SM controller types. The choice of the state variable is critical for the successful implementation of the PWM based SM controller. Finally, similar to conventional controllers, the physical limitation of the analog devices, e.g. bandwidths, propagation time delays, slew rates, and saturation limits of the SM controller should be properly noted. They are the key factors affecting the healthy operation of the SM controller.

\section{Practical Design Guides}

Since SM control achieves order reduction, it is sufficient to have an SM controller of $n-1$ order for the stable control of an $n$ order converter. However, as earlier mentioned, the use of fixed-frequency SM controllers deteriorates the robustness and regulation properties of the system. In theory, this can be solved by adopting an additional integral control variable into the SM controller, which is also known as integral or fullorder SM control [1]. Hence, as a basic guideline in terms of ease of implementation and good control performance, a good option is to adopt an SM controller that employs a linear combination of the system states which has the same order as the converter. Now, assuming that a full-order SM controller is designed for a second-order converter, the control function of such a second-order controller is

$$
u= \begin{cases}u^{+} & \text {when } S>0 \\ u^{-} & \text {when } S<0\end{cases}
$$

where $u$ is the logic state of the converter's power switch and $S$ is the instantaneous state variable's trajectory, given by

$$
S=\alpha_{1} x_{1}+\alpha_{2} x_{2}+\alpha_{3} x_{3},
$$

where $\alpha_{1}, \alpha_{2}$, and $\alpha_{3}$ represent the sliding coefficients, and $x_{1}, x_{2}$, and $x_{3}$ denote the desired state feedback variables to be controlled. The task of the designer is to determine the state of $u^{+} / u^{-}$and to select proper parameters for $\alpha_{1}, \alpha_{2}$, and $\alpha_{3}$ such that the controller meets the hitting, existence, 
and stability conditions for all system's operating input and loading conditions.

\section{Step 1: To Meet Hitting Condition}

The design of the SM controller to meet the hitting condition is rather straightforward in the case of power converters. Assuming the output voltage to be the control variable, the state variables of the full-order SM controller to be controlled may be expressed in the following form:

$$
\left[\begin{array}{l}
x_{1} \\
x_{2} \\
x_{3}
\end{array}\right]=\left[\begin{array}{c}
V_{\text {ref }}-\beta v_{\mathrm{o}} \\
\frac{d\left(V_{\mathrm{ref}}-\beta v_{\mathrm{o}}\right)}{d t} \\
\int\left(V_{\mathrm{ref}}-\beta v_{\mathrm{o}}\right) d t
\end{array}\right]
$$

where $V_{\text {ref }}$ and $\beta v_{\mathrm{o}}$ denote the reference and sensed instantaneous output voltages respectively; and $x_{1}, x_{2}$, and $x_{3}$ are the voltage error, the voltage error dynamics (or the rate of change of voltage error), and the integral of voltage error, respectively. For the design of the hitting condition, it is sufficient to consider only the immediate state variable $x_{1}$, which is predominant in the composition of $S$ during the reaching phase. Apparently, if the sensed output voltage is much lower than the reference voltage, i.e., $S$ is positive, the intuitive switching action required for the compensation is to turn on the power switch so that energy is transferred from the input source to the inductor. Conversely, if the sensed output voltage is much higher than the reference voltage, i.e., $S$ is negative, the intuitive switching action is to turn off the power switch so that energy transfer between the source and the inductor is discontinued. This forms the basis for the formulation of the hitting condition. The resulting control function under the configuration is

$$
u=\left\{\begin{array}{ll}
1=\text { 'ON' } & \text { when } S>0 \\
0=\text { 'OFF' } & \text { when } S<0
\end{array} .\right.
$$

Clearly, the method of ensuring the hitting condition of the SM controller is similar to the way in which the switching states of conventional hysteresis controller are designed.

\section{Step 2: To Meet Existence Condition}

With the switching states $u^{+} / u^{-}$determined, the next stage is to ensure that the selected sliding coefficients $\alpha_{1}, \alpha_{2}$, and $\alpha_{3}$ comply with the condition for SM existence. This is possible by inspecting the local reachability condition of the state trajectory, i.e.,

$$
\lim _{S \rightarrow 0} S \cdot \dot{S}<0 .
$$

In the case of the buck converter, the substitution of the converter's description into the above condition gives

$$
\begin{aligned}
0<L C \frac{\alpha_{3}}{\alpha_{2}}\left(V_{\text {ref }}-\beta v_{\mathrm{o}}\right)-\beta L\left(\frac{\alpha_{1}}{\alpha_{2}}-\frac{1}{r_{\mathrm{L}} C}\right) i_{C} & +\beta v_{\mathrm{o}} \\
& <\beta v_{\mathrm{i}}
\end{aligned}
$$

where $C, L$, and $r_{\mathrm{L}}$ denote the capacitance, inductance, and instantaneous load resistance respectively; $v_{\mathrm{i}}$ denotes the instantaneous input voltage; and $i_{C}$ denotes the instantaneous capacitor current. Here, $C, L, \beta, V_{\text {ref }}$ are known parameters of the converter system and their exact values can be substituted directly into the inequality for inspection. However, for $v_{\mathrm{i}}$ and
$r_{\mathrm{L}}$ which typically represent a range of input and output operating conditions that the converter may engage, it is necessary to consider the boundary points of these operating conditions. The compliance of either the maximum or minimum point of these operating conditions is generally sufficient for ensuring the abidance of the existence condition for the entire range of condition. As for $v_{\mathrm{o}}$ and $i_{C}$, which are instantaneous state variables, the consideration of the time varying nature of these components undesirably complicates the evaluation. In the case of designing an SM controller with a static sliding surface, a practical approach is to ensure that the existence condition is met for the steady-state operation [21], [44]. With such considerations, the state variables $i_{C}$ and $v_{\mathrm{o}}$ can be substituted with their expected steady-state parameters, i.e., $i_{C(\mathrm{SS})}$ and $v_{\mathrm{o}(\mathrm{SS})}$, which can be derived from the design specification. This assures the compliance of the existence condition at least in the small region around the origin.

\section{Step 3: To Meet Stability Condition}

In addition to the existence condition, the selected sliding coefficients must concurrently abide the stability condition. This is to ensure that in the event of SM operation, the created sliding surface will always direct the state trajectory towards a point where a stable equilibrium exists. Interestingly, this can be inherently accomplished through the design of the sliding coefficients to meet the desired dynamical property [70]. This is possible by using the invariance property. Since it is known that in SM operation, the state trajectory $S$ will track the path of the sliding surface to a point of stability, an equation describing the dynamical property of the system can be obtained by equating the state trajectory to this sliding surface, i.e., by setting $S=0$. The proper selection of the sliding coefficients will tailor the system to respond as desired by the designer. It follows that the stability condition is inherently met.

\section{CASE Study Discussions}

It was shown in [67] through a comparison between the classical PWM voltage controlled buck converter and the PWM based SM voltage controlled buck converter that a major difference between a large-signal controlled system (SM) and a small-signal controlled system (PWM) is that the former complies to the design with a similar response for all operating conditions, while the response of the latter will only comply to the design at a specific operating condition. Here, we introduce a second example from the paper [68] to further the discussion. The dynamic behavior of the PWM based controller is compared to that of a UC3843 peak current mode PWM controller that is optimally tuned to operate a $48 \mathrm{~V}$ boost converter for a step load change of $r_{\mathrm{L}}=240 \Omega$ to $r_{\mathrm{L}}=24 \Omega$ at the input condition $v_{\mathrm{i}}=24 \mathrm{~V}$.

Figs. 1(a)-1(i) show the experimental waveforms of the boost converter with the peak current mode controller. It can be seen that the dynamic behavior of the system differs for different operating conditions. Specifically, the response becomes less oscillatory at higher input voltages. Moreover, the dynamic behavior and transient settling time are also different between the various cases of operating conditions. 


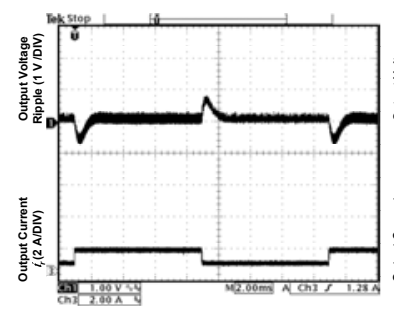

(a) $v_{\mathrm{i}}=20 \mathrm{~V}(0.2 / 1.0 \mathrm{~A})$

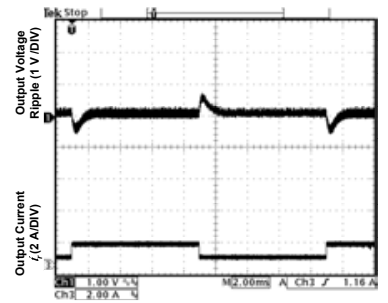

(d) $v_{\mathrm{i}}=24 \mathrm{~V}(0.2 / 1.0 \mathrm{~A})$

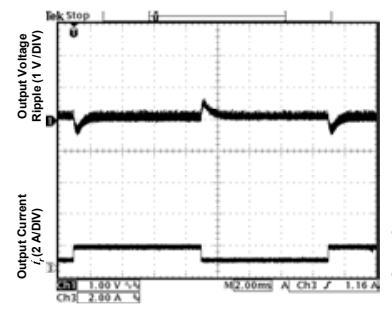

(g) $v_{\mathrm{i}}=28 \mathrm{~V}(0.2 / 1.0 \mathrm{~A})$

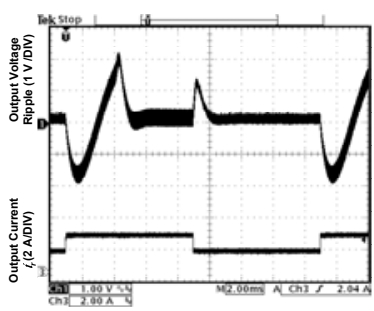

(b) $v_{\mathrm{i}}=20 \mathrm{~V}(1.0 / 2.0 \mathrm{~A})$

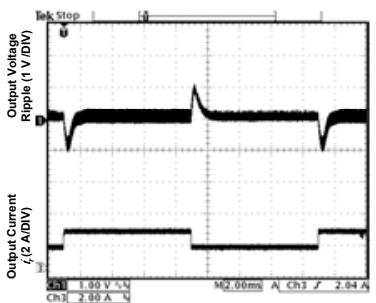

(e) $v_{\mathrm{i}}=24 \mathrm{~V}(1.0 / 2.0 \mathrm{~A})$

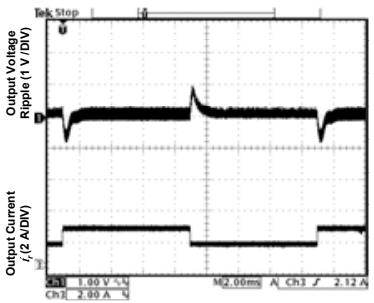

(h) $v_{\mathrm{i}}=28 \mathrm{~V}(1.0 / 2.0 \mathrm{~A})$

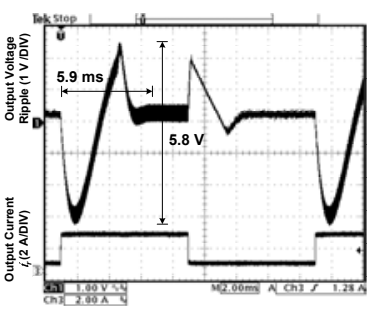

(c) $v_{\mathrm{i}}=20 \mathrm{~V}(0.2 / 2.0 \mathrm{~A})$

Fig. 1. Experimental waveforms of the boost converter with the peak current mode controller.

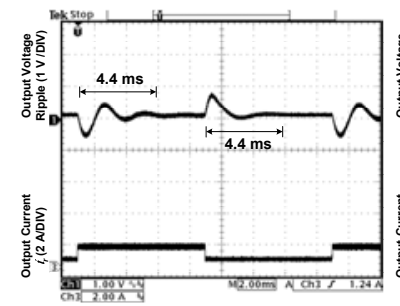

(a) $v_{\mathrm{i}}=20 \mathrm{~V}(0.2 / 1.0 \mathrm{~A})$

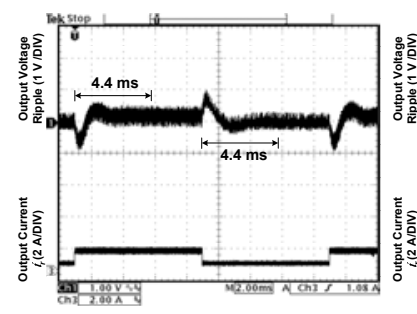

(d) $v_{\mathrm{i}}=24 \mathrm{~V}(0.2 / 1.0 \mathrm{~A})$

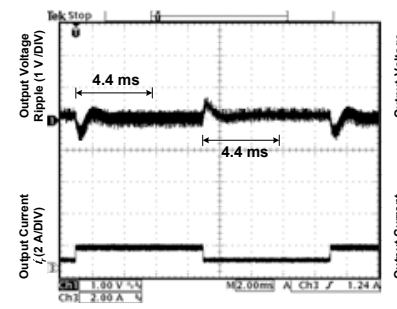

(g) $v_{\mathrm{i}}=28 \mathrm{~V}(0.2 / 1.0 \mathrm{~A})$

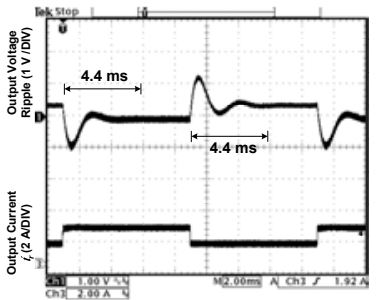

(b) $v_{\mathrm{i}}=20 \mathrm{~V}(1.0 / 2.0 \mathrm{~A})$

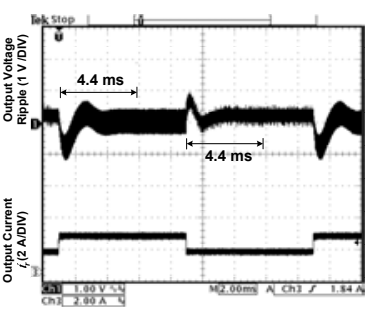

(e) $v_{\mathrm{i}}=24 \mathrm{~V}(1.0 / 2.0 \mathrm{~A})$

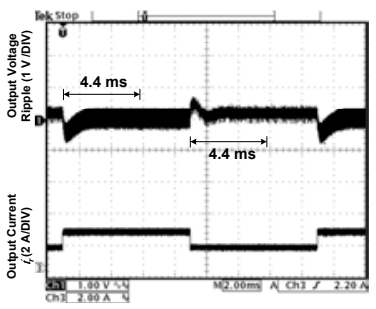

(h) $v_{\mathrm{i}}=28 \mathrm{~V}(1.0 / 2.0 \mathrm{~A})$

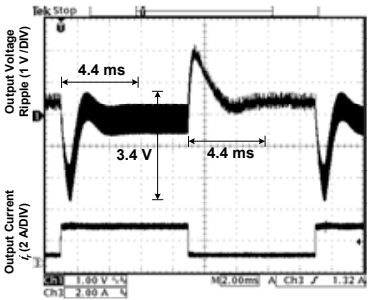

(c) $v_{\mathrm{i}}=20 \mathrm{~V}(0.2 / 2.0 \mathrm{~A})$

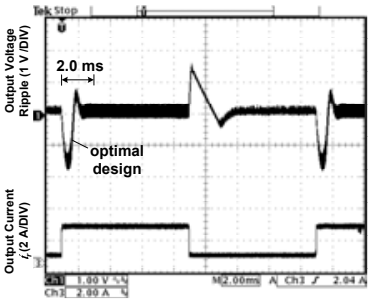

(f) $v_{\mathrm{i}}=24 \mathrm{~V}(0.2 / 2.0 \mathrm{~A})$

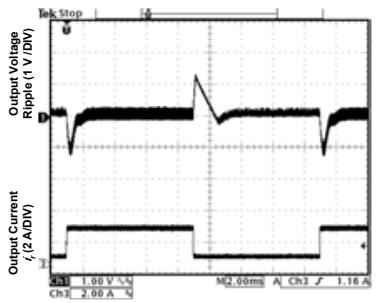

(i) $v_{\mathrm{i}}=28 \mathrm{~V}(0.2 / 2.0 \mathrm{~A})$

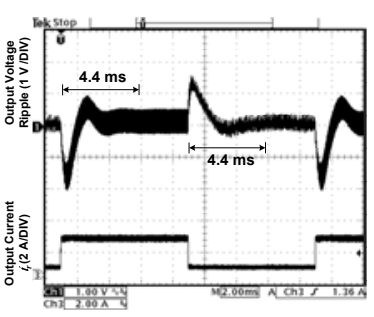

(f) $v_{\mathrm{i}}=24 \mathrm{~V}(0.2 / 2.0 \mathrm{~A})$

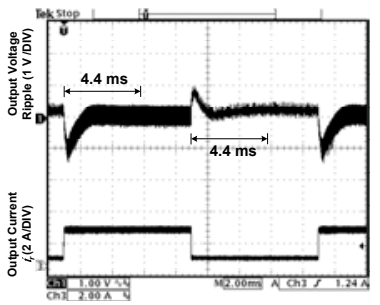

(i) $v_{\mathrm{i}}=28 \mathrm{~V}(0.2 / 2.0 \mathrm{~A})$

Fig. 2. Experimental waveforms of the boost converter with the $1.5 \mathrm{krad} / \mathrm{s}$ bandwidth PWM based SM controller. 
On the other hand, with the PWM based SM controller, the dynamic behavior of output voltage ripple is basically similar (i.e. slightly under-damped) for all operating input and load conditions. This is illustrated in Figs. 2(a)-2(i). Furthermore, the transient settling time, which is around $4.4 \mathrm{~ms}$, is also independent of the direction and magnitude of the step load change and the operating input voltages. It reinforces our belief that a main advantage of the large-signal controller (SM) over the small-signal controller (PWM) is that it gives more consistent dynamic performances for operating conditions requiring wide ranges.

\section{CONCLUSION}

The various aspects concerning the application of sliding mode controllers in DC-DC converters are presented. A comprehensive literature review on the area is provided. The issues related to the analog implementation of the sliding mode controller is discussed. The advantage of using sliding mode controller is highlighted. It is shown that the sliding mode controllers generate more consistent transient responses for a wide operating range as compared to conventional PWM controllers.

\section{REFERENCES}

[1] V. Utkin, J. Guldner, and J.X. Shi, Sliding Mode Control in Electromechanical Systems. London, U.K.: Taylor and Francis, 1999.

[2] V. Utkin, Sliding Modes in Control Optimization. Berlin: SpringerVerlag, 1992.

[3] C. Edwards and S.K. Spurgeron, Sliding Mode Control: Theory and Applications. London, U.K.: Taylor and Francis, 1998.

[4] W. Perruquetti and J.P. Barbot, Sliding Mode Control in Engineering. New York, NY: Marcel Dekker, 2002.

[5] J.J.E. Slotine and W. Li, "Sliding Control", Ch. 7, Applied Nonlinear Control. Englewood Cliffs, N.J.: Prentice -Hall, Inc., 1991.

[6] R. Venkataramanan, "Sliding mode control of power converters," $\mathrm{PhD}$ Thesis, California Institute of Technology, Department of Electrical Engineering, Pasadena, California, May 1986.

[7] R.D. Middlebrook and S. Ćuk, "A general unified approach to modeling switching power converter stages," in IEEE Power Electronics Specialists Conference Record (PESC), pp. 18-34, 1976.

[8] D.M. Mitchell, DC-DC Switching Regulator Analysis. New York: McGraw Hill, 1998.

[9] A.J. Forsyth and S.V. Mollow, "Modelling and control of DC-DC converters," IEE Power Engineering Journal, vol. 12 no. 5, pp. 229236, Oct 1998.

[10] J.G. Kassakian, M.F. Schlecht, and G.C. Verghese, Principles of Power Electronics. Reading, Mass.: Addison-Wesley, June 1992.

[11] F. Bilalović, O. Mušić, and A. Šabanović, "Buck converter regulator operating in the sliding mode," in Proceedings, Seventh International Conference on Power Conversion (PCI), pp. 331-340, April 1983.

[12] R. Venkataramanan, A. Šabanović, and S. Cuk, "Sliding mode control of DC-to-DC converters," in Proceedings, IEEE Conference on Industrial Electronics, Control and Instrumentations (IECON), pp. 251-258, 1985.

[13] S.P. Huang, H.Q. Xu, and Y.F. Liu, "Sliding-mode controlled Ćuk switching regulator with fast response and first-order dynamic characteristic "' in IEEE Power Electronics Specialists Conference Record (PESC), pp. 124-129, June 1989.

[14] E. Fossas, L. Martínez and J. Ordinas, " Sliding mode control reduces audiosusceptibility and load perturbation in the Cuk converter," IEEE Transactions on Circuits and Systems Part I: Fundamental Theory and Applications, , vol. 39 no. 10, pp. 847-849, Oct 1992.

[15] L. Malesani, L. Rossetto, G. Spiazzi, and P. Tenti, "Performance optimization of Ćuk converters by sliding-mode control," IEEE Transactions on Power Electronics, vol. 10 no. 3, pp. 302-309, May 1995.

[16] M. Oppenheimer, M. Husain, M. Elbuluk, and J.A.De Abreu Garcia, "Sliding mode control of the Cuk converter," in IEEE Power Electronics Specialists Conference Record (PESC), vol. 2, pp. 1519-1526, June 1996.
[17] J. Mahdavi and A. Emadi, "Sliding-mode control of PWM Ćuk converter," in Proceedings, Sixth International Conference on Power Electronics and Variable Speed Drives, vol. 2, pp. 372-377, Sep. 1996.

[18] J. Calvente, L. Martinez, and R. Giral, "Design of locally stable sliding modes in bidirectional switching converters," in Proceedings, 40th Midwest Symposium on Circuits and Systems, vol. 1, pp. 615-618, Aug. 1997.

[19] L. Martinez-Salamero, J. Calvente, R. Giral, A. Poveda, and E. Fossas, "Analysis of a bidirectional coupled-inductor Ćuk converter operating in sliding mode," IEEE Transactions on Circuits and Systems Part I: Fundamental Theory and Applications, vol. 45, no. 4, pp. 355-363, April 1998.

[20] P. Mattavelli, L. Rossetto, G. Spiazzi, and P. Tenti, "General-purpose sliding-mode controller for DC/DC converter applications," in IEEE Power Electronics Specialists Conference Record (PESC), pp. 609-615, June 1993

[21] P. Mattavelli, L. Rossetto, and G. Spiazzi, "Small-signal analysis of DCDC converters with sliding mode control," IEEE Transactions on Power Electronics, vol. 12 no. 1, pp. 96-102, Jan. 1997.

[22] F. Dominguez, E. Fossas, and L. Martinez, "Stability analysis of a buck converter with input filter via sliding-mode approach," in Proceedings, IEEE Conference on Industrial Electronics, Control and Instrumentations (IECON), pp. 1438-1442, Sep 1994.

[23] M. Castilla, L.C. de Vicuna, M. Lopez, O. Lopez, and J. Matas, "On the design of sliding mode control schemes for quantum resonant converters," IEEE Transactions on Power Electronics, vol. 15 no. 15, pp. 960-973, Nov. 2000.

[24] P.F. Donoso-Garcia, P.C. Cortizo, B.R. de Menezes, and M.A. Severo Mendes, "Sliding mode control for current distribution in DC-to-DC converters connected in parallel," in IEEE Power Electronics Specialists Conference Record (PESC), pp. 1513-1518, June 1996.

[25] Y.B. Shtessel, O.A. Raznopolov, and L.A. Ozerov, "Sliding mode control of multiple modular DC-to-DC power converters," in Proceedings, IEEE International Conference on Control Applications, pp. 685-690, Dec 1996.

[26] Y.B. Shtessel, O.A. Raznopolov, and L.A. Ozerov, "Control of multiple modular DC-to-DC power converters in conventional and dynamic sliding surfaces," IEEE Transactions on Circuits and Systems Part I: Fundamental Theory and Applications, vol. 45, no. 10, pp. 1091-1100, Oct. 1998

[27] M. López, L.G. De-Vicuňa, M. Castilla, and J. Majo, "Interleaving of parallel DC-DC converters using sliding mode control," in Proceedings, IEEE Conference on Industrial Electronics, Control and Instrumentations (IECON), pp. 1055-1059, Sep 1998.

[28] R. Giral, L. Martinez-Salamero, R. Leyva, and J. Maixe, "Sliding-mode control of interleaved boost converters," IEEE Transactions on Circuits and Systems Part I: Fundamental Theory and Applications, vol. 47, no. 9, pp. 1330-1339, Sep. 2000.

[29] S.K. Mazumder, A.H. Nayfeh, A. Borojevic, P. Gaya, and O. López, "Robust control of parallel DC-DC buck converters by combining integral-variable-structure and multiple-sliding-surface control schemes," IEEE Transactions on Power Electronics, vol. 17, no. 3, pp. 428-437, May 2002.

[30] M. López, L.G. De-Vicuňa, M. Castilla, P. Gaya, and O. López, "Current distribution control design for paralleled DC/DC converters using sliding-mode control," IEEE Transactions on Industrial Electronics, vol. 45, no. 10, pp. 1091-1100, Apr. 2004.

[31] S.K. Mazumder and S.L. Kamisetty, "Design and experimental validation of a multiphase VRM controller", in Proceedings, IEE Electric Power Applications, vol. 152, no. 5, pp. 1076-1084, Sep. 2005.

[32] H. Sira-Ramirez and M. Rios-Bolivar, "Sliding mode control of DC-toDC power converters via extended linearization," IEEE Transactions on Circuits and Systems Part I: Fundamental Theory and Applications, , vol. 41 no. 10, pp. 652-661, Oct 1994.

[33] H. Sira-Ramirez, R. Ortega, R. Perez-Moreno, and M. Garcia-Esteban, "A sliding mode controller-observer for DC-to-DC power converters: a passivity approach," in Proceedings, The 34th IEEE Conference on Decision and Control, pp. 3379-3384, Dec 1995.

[34] H. Sira-Ramirez, G. Escobar, and R. Ortega, "On passivity-based sliding mode control of switched DC-to-DC power converters," in Proceedings, The 35th IEEE Conference on Decision and Control, pp. 2525-2526, Dec 1996.

[35] E. Fossas and D. Biel, "A sliding mode approach to robust generation on DC-to-DC nonlinear converters," in Proceedings, IEEE International Workshop on Variable Structure Systems, pp. 67-71, Dec 1996.

[36] J.M. Carrasco, J.M. Quero, F.P. Ridao, M.A. Perales, and L.G. Franquelo, "Sliding mode control of a DC/DC PWM converter with PFC 
implemented by neural networks," IEEE Transactions on Circuits and Systems Part I: Fundamental Theory and Applications, , vol. 44 no. 8, pp. 743-749, Aug. 1997.

[37] S.A. Bock, J.R. Pinheiro, H. Grundling, H.L. Hey, and H. Pinheiro, "Existence and stability of sliding modes in bi-directional DC-DC converters," in IEEE Power Electronics Specialists Conference Record (PESC), vol. 3, pp. 1277-1282, June 2001.

[38] E. Fossas and A. Pas, "Second order sliding mode control of a buck converter," in Proceedings, The 41st IEEE Conference on Decision and Control, vol. 1, pp. 346-347, Dec. 2002.

[39] Y.B. Shtessel, A.S.I. Zinober, and I.A. Shkolnikov, "Boost and buckboost power converters control via sliding modes using method of stable system centre," in Proceedings, The 41st IEEE Conference on Decision and Control, vol. 1, pp. 340-345, Dec 2002.

[40] Y.B. Shtessel, A.S.I. Zinober, and I.A. Shkolnikov, "Boost and buckboost power converters control via sliding modes using dynamic sliding manifold," in Proceedings, The 41st IEEE Conference on Decision and Control, vol. 3, pp. 2456-2461, Dec 2002.

[41] N. Vazquez, C. Hernandez, J. Alvarez, and J. Arau, "Sliding mode control for DC/DC converters: a new sliding surface," in Proceedings, IEEE International Symposium on Industrial Electronics, vol. 1, pp. 422-426, June 2003.

[42] P. Gupta, and A. Patra, "Hybrid sliding mode control of DC-DC power converter circuits," in Proceedings, IEEE Region Ten Conference on Convergent Technologies for Asia-Pacific Region, vol. 1, pp. 259-263, Oct. 2003.

[43] H. Sira-Ramirez, "Sliding mode- $\Delta$ modulation control of a "buck converter"," in Proceedings, The 42nd IEEE Conference on Decision and Control, vol. 3, pp. 2999-3004, Dec. 2003.

[44] H. Sira-Ramirez, "On the generalized PI sliding mode control of DCto-DC power converters: a tutorial," International Journal of Control, vol. 76 no. 9/10, pp. 1018-1033, 2003.

[45] V.S.C. Raviraj and P.C. Sen, "Comparative study of proportionalintegral, sliding mode, and fuzzy logic controllers for power converters," IEEE Transactions on Industry Applications, vol. 33, no. 2, pp. 518-524, March/April 1997.

[46] D. Cortes and J. Alvarez, "Robust sliding mode control for the boos converter," in Proceedings, IEEE International CIEP Power Electronics Congress, pp. 208-212, Oct 2002

[47] C. Morel, J.C. Guignard, and M. Guillet, "Sliding mode control of DCto-DC power converters," in Proceedings, 9th International Conference on Electronics, Circuits and Systems, vol. 3, pp. 971-974, Sep 2002

[48] C. Morel, "Slide mode control via current mode control in DC-DC converters," in Proceedings, IEEE International Conference on Systems, Man and Cybernetics, vol. 5, pp. 6-11, Oct 2002.

[49] C. Morel, "Application of slide mode control to a current-modecontrolled boost converter," in Proceedings, IEEE Conference on Industrial Electronics, Control and Instrumentations (IECON), vol. 3, pp. 1824-1829, Nov 2002

[50] G. Escobar, R. Ortega, H. Sira-Ramirez, J.P. Vilain, and I. Zein, "An experimental comparison of several nonlinear controllers for power converters," IEEE Control Systems Magazine, vol. 19, no. 1, pp. 6682, February 1999

[51] H. Chiacchiarini, P. Mandolesi, and A. Oliva, "Nonlinear analog controller for a buck converter: theory and experimental results," in Proceedings, IEEE International Symposium on Industrial Electronics, pp. 601606, July 1999.

[52] E. Alarcon, A. Romero, A. Poveda, S. Porta, and L. Martinez-Salamero "Sliding-mode control analog integrated circuit for switching DC-DC power converters," in Proceedings, IEEE International Symposium on Circuits and Systems, pp. 500-503, May 2001.

[53] M. Ahmed, M. Kuisma, K. Tolsa, and P. Silventoinen, "Implementing sliding mode control for buck converter," in IEEE Power Electronics Specialists Conference Record (PESC), vol. 2, pp. 634-637, June 2003.

[54] M. Ahmed, M. Kuisma, P. Silventoinen, and O. Pyrhonen, "Effect of implementing sliding mode control on the dynamic behavior and robustness of switch mode power supply (buck converter)," in Proceedings, The Fifth International Conference on Power Electronics and Drive Systems, vol. 2, pp. 1364-1368, Nov. 2003.
[55] M. Ahmed, M. Kuisma, O. Pyrhonen, and P. Silventoinen, "Sliding mode control for buck-boost converter using control desk dSPACE," in Proceedings, The Fifth International Conference on Power Electronics and Drive Systems, vol. 2, pp. 1491-1494, Nov. 2003.

[56] B.J. Cardoso, A.F. Moreira, B.R. Menezes, and P.C. Cortizo, "Analysis of switching frequency reduction methods applied to sliding mode controlled DC-DC converters," in Proceedings, IEEE Applied Power Electronics Conference and Exposition (APEC), pp. 403-410, Feb 1992.

[57] V.M. Nguyen and C.Q. Lee, "Tracking control of buck converter using sliding-mode with adaptive hysteresis," in IEEE Power Electronics Specialists Conference Record (PESC), vol. 2, pp. 1086-1093, June 1995.

[58] V.M. Nguyen and C.Q. Lee, "Indirect implementations of sliding-mode control law in buck-type converters," in Proceedings, IEEE Applied Power Electronics Conference and Exposition (APEC), vol. 1, pp. 111115, March 1996.

[59] J. Mahdavi, A. Emadi, and H.A. Toliyat, "Application of state space averaging method to sliding mode control of PWM DC/DC converters," in Proceedings, IEEE Conference on Industry Applications (IAS), vol. 2, pp. 820-827, Oct. 1997.

[60] J. Mahdavi, M.R. Nasiri, and A. Agah, "Application of neural networks and state space averaging to a DC/DC PWM converter in sliding mode operation," in Proceedings, IEEE Conference on Industrial Electronics, Control and Instrumentations (IECON), vol. 1, pp. 172-177, 2000.

[61] A.G. Perry, F. Guang, Y.F Liu, and P.C. Sen, "A new sliding mode like control method for buck converter," in IEEE Power Electronics Specialists Conference Record (PESC), vol. 5, pp. 3688-3693, June 2004.

[62] L. Iannelli and F. Vasca, "Dithering for sliding mode control of DC/DC converters," in IEEE Power Electronics Specialists Conference Record (PESC), vol. 2, pp. 1616-1620, June 2004.

[63] J. Matas, L.G. De-Vicuňa, O. López, and M. López, "Discrete sliding mode control of a boost converter for output voltage tracking," in Proceedings, Eighth International Conference on Power Electronics and Variable Speed Drives, pp. 351-354, Sep 2000.

[64] R. Orosco and N. Vazquez, "Discrete sliding mode control for DC/DC converters," in Proceedings, IEEE International CIEP Power Electronics Congress, pp. 231-236, Oct 2000.

[65] S.C. Tan, Y.M. Lai, M.K.H. Cheung, and C. K. Tse, "On the practical design of a sliding mode voltage controlled buck converter", IEEE Transactions on Power Electronics, vol. 20, no. 2, pp. 425-437, Mar. 2005.

[66] S.C. Tan, Y.M. Lai, C. K. Tse, and M.K.H. Cheung, "Adaptive feedforward and feedback control schemes for sliding mode controlled power converters", IEEE Transactions on Power Electronics, vol. 21, no. 1, pp. 182-192, Jan. 2006.

[67] S.C. Tan, Y.M. Lai, C.K. Tse, and M.K.H. Cheung, "A fixed-frequency pulse-width-modulation based quasi-sliding mode controller for buck converters", IEEE Transactions on Power Electronics, vol. 20, no. 6, pp. 1379-1392, Nov. 2005.

[68] S.C. Tan, Y.M. Lai, and Chi K. Tse, "A unified approach to the design of PWM based sliding mode voltage controller for basic DC-DC converters in continuous conduction mode", IEEE Transactions on Circuits and Systems I, to appear.

[69] S.C. Tan, Y.M. Lai, and C.K. Tse, "Implementation of pulse-widthmodulation based sliding mode controller for boost converters", IEEE Power Electronics Letter, vol. 3, no. 4, pp. 130-135, Dec. 2005.

[70] J. Ackermann and V. Utkin, "Sliding mode control design based on Ackermann's formula," IEEE Transactions on Automatic Control, vol. 43 no. 2, pp. 234-237, Feb. 1998.

[71] H. Sira-Ramirez, "A geometric approach to pulse-width modulated control in nonlinear dynamical systems," IEEE Transactions on Automatic Control, vol. 34 no. 3, pp. 184-187, Feb. 1989.

[72] L. Martinez, A. Poveda, J. Majo, L. Garcia-de-Vicuna, F. Guinjoan, J.C. Marpinard, and M. Valentin, "Lie algebras modelling of bidirectional switching converters," in Proceedings, European Conference on Circuit Theory and Design (ECCTD), vol. 2, pp. 1425-1429, Sep. 1993. 